\title{
Multivariate analysis of morphological descriptors for identification of Sesbania Scop. accessions
}

\author{
S. C. Chanda ${ }^{1,2}$, Md. A. $\operatorname{Razzak}^{1}$, Md. E. Haque ${ }^{2,3}$ and A. K. M. Golam Sarwar ${ }^{1 *}$ \\ ${ }^{1}$ Laboratory of Plant Systematics, Department of Crop Botany, Bangladesh Agricultural University, Mymensingh, Bangladesh \\ ${ }^{2}$ Department of Agriculture Extension, Sirajganj, Bangladesh \\ ${ }^{3}$ Bangladesh Agricultural Research Institute, Pabna, Bangladesh
}

Received: 05 January 2020

Revised: 18 February 2020

Accepted: 08 July 2020

DOI: $10.3329 /$ bjsir.v55i3.49395

\begin{abstract}
Based on the 36 quantitative morphological descriptors, agglomerative hierarchical clustering (AHC) and principal component analyses (PCA) were conducted to identify 106 diverse Sesbania accessions. The AHC analysis identified three major clusters with 11 sub-clusters. In PCA, the first and second PCs explain $72.48 \%$ and $12.72 \%$ of total variations with high Eigen value 9.1 and 1.7 , respectively. Sesbania accessions occupied four distinct positions in the PCA graph. Based on multivariate analyses and qualitative descriptors, Sesbania accessions have been identified as $S$. bispinosa (90 accessions), S. cannabina (9 accessions), S. sesban (6 accessions) and the known $S$. rostrata. The AHC dendrogram has detected the close similarities between $S$. rostrata and $S$. cannabina. However, the PCA has emerged to be better than the AHC as a species identification tool. Among these four species, the highest discriminating distance $(23.69 \%)$ was observed between $S$. sesban and S. bispinosa, and the lowest (10.52\%) was in S. bispinosa and S. cannabina.
\end{abstract}

Keywords: Sesbania Scop.; Numerical data; Agglomerative hierarchical clustering; Principal component analysis; Dissimilarities distance

\section{Introduction}

The genus Sesbania Scop. consists of ca. 85 species, encompassing annuals, perennials, herbs, shrubs and trees having nodules in 40 species, which are widely distributed in tropical and subtropical regions of the world (Evans, 1990; Farruggia et al., 2018). Africa and Madagascar possess the richest species diversity of Sesbania with 32 species followed by Australia and tropical Asia (10 species each) and the Neo-tropics (southern USA to northern Argentina, especially North and Central America) with nine species (Veasey et al., 1999; Farruggia et al., 2018). In Bangladesh, Sesbania is represented by five species viz. S. bispinosa (Jacq.) W. Wight [former S. aculeata (Wild.) Pers.], S. cannabina (Retz.) Pers., S. grandiflora (L.) Pers., S. javanica Miq. and S. sesban (L.) Merr.; and three species viz. S. bispinosa, S. cannabina and $S$. sesban, are commonly known as dhaincha (Ahmed et al. 2009; Sarwar et al., 2015). Sesbania, one of the most important green manure and fodder crops in most of the tropical world including Bangladesh, is sometimes called as miracle plant for its multipurpose economic and medicinal uses (Farruggia et al., 2018; Sarwar, 2018).

Morphological characterization has been considered as a primary tool for a better understanding of its genetic diversity and determining the relationship among the genotypes (Karp et al., 1997). Morphological descriptors are also the most widely used for characterization and identification of the natural variations (Nurul et al., 2014; Chanda et al., 2019a). Agglomerative hierarchical cluster (AHC) and principal component analyses (PCA) are appropriate multivariate techniques which help to determine effective descriptors for indirect selection of better genotypes (Lever et al., 2017; Mehraj and Shimasaki, 2017; Kane et al., 2019). 
The identification of Sesbania species is difficult in the field due to continuous variations in morphological descriptors (Chanda, 2019). A series of paper on utility of morphological, both qualitative and quantitative, descriptors for different aspects of the identification of closely related Sesbania species were published by our group (Chanda et al. 2017, 2018a, b, 2019b; Sarwar et al., 2015). Here, we had emphasized on the multivariate analyses techniques for quantitative morphological descriptors as a tool for identification of Sesbania accessions.

\section{Materials and methods}

The experiment was conducted at Field and Plant Systematics Laboratories of the Department of Crop Botany, Bangladesh Agricultural University during 2017 to identify 106 Sesbania accessions, including an exotic $S$. rostrata Bremek and Oberm. accession, using quantitative descriptors through multivariate analyses. Seeds of Sesbania accessions were collected from different regions of Bangladesh (collection information available upon request). The detail of field experimental procedures have described in Chanda et al. (2019b). Numerical data on total $36 \mathrm{viz} .7$ seed and seedling, 10 vegetative, 3 phenology and 16 reproductive, morphological descriptors were collected and used for analyses (Table I). The data was collected as part of agro-morphological characterization of dhaincha genetic resources of Bangladesh for the improvements of soil nutrients status (Chanda, 2019).

The agglomerative hierarchical cluster (AHC) analysis was performed on the dissimilarity of accession characteristics and the dendrogram were generated using XLStat software program (https://www.xlstat.com/en/). Principal component analysis (PCA) and non-metric multi dimensional scaling (NMDS) analyses were performed by using PAST (Paleontological Statistics) software package (Hammer-Muntz et al., 2001). Two principal components with the highest Eigen value were used to produce scatter plot for quantitative characteristics.

\section{Results and discussion}

In the AHC analysis, 106 accessions of Sesbania species were separated in three major groups/clusters and these major clusters further divided into eleven sub-clusters (Fig. 1). The highest number (58) of accessions contained in cluster \#1 and the lowest number (6) in cluster \#3. Among the sub-clusters, sub-cluster \#7 contained the highest (14) number of accessions and the lowest (1) in sub-cluster \#10 (Fig. 1). It might indicate that many of these accessions have similarities in morphological descriptors. Sneath (1969) opinioned that accessions showed a high level of homogeneity within a cluster. The cluster \#3 comprised six accessions (\#66, 70, 79, 81,82 and 85) and these may belong to a species. Chanda et al. $(2018 \mathrm{a}, \mathrm{b})$ also reported that accession \#70, 79, 81, 82 and 85 always remain in the same cluster. Clusters \#1 and 2 were divided into 11 sub-clusters. The sub-cluster \#10 includes only known exotic species $S$. rostrata (accession \#105) and the sub-cluster \#11 includes accession \#26, 22, 24, 25, 28, 91, 116, 117 and 118 (Fig. 1; Chanda et al., 2018a). Morphological descriptors of accession \#105 were similar to accession \#66, 70, 79, 81, 82 and 85 (Fig. 2). Therefore, accessions of sub-cluster \#11 might belong to another species

Table I. Vegetative and reproductive descriptors of Sesbania species

\begin{tabular}{lll}
\hline Sl. No. & Data Source & \multicolumn{1}{c}{ Descriptors } \\
\hline 1 & Seed and & Seed length and width $(\mathrm{mm})$ \\
2 & seedling & Germination $(\%)$ \\
3 & descriptors & Vigor index \\
4 & & Seedling length $(\mathrm{cm})$ \\
5 & & 1000 -seed weight $(\mathrm{g})$ \\
6 & & Seedling fresh weight $(\mathrm{g})$ \\
7 & & Seedling dry weight $(\mathrm{g})$ \\
8 & Growth & Plant height $(\mathrm{cm})$ \\
9 & descriptors & Base diameter $(\mathrm{cm})$ \\
10 & (60 days & Internodes number $/$ plant \\
11 & after sowing) & Internodes length $(\mathrm{cm})$ \\
12 & & Number of leaves $/$ plant \\
13 & & Leaf length and width $(\mathrm{cm})$ \\
14 & & Number of leaflets $/$ leaf \\
15 & & Leaflet length and width $(\mathrm{cm})$ \\
16 & & Plant fresh weight $(\mathrm{g})$ \\
17 & & Plant biomass $(\mathrm{g})$ \\
18 & Phenological & Inflorescences initiation time \\
\hline
\end{tabular}

\begin{tabular}{lll}
\hline Sl. No. & \multicolumn{1}{c}{ Source } & \multicolumn{1}{c}{ Descriptors } \\
\hline 19 & descriptors & First flower opening time (d) \\
20 & & Flowering time $(50 \%)(\mathrm{d})$ \\
21 & Reproductive & Inflorescence length $(\mathrm{mm})$ \\
22 & descriptors & Number of flowers /inflorescence \\
23 & & Flower length (mm) \\
24 & Petiole length (mm) \\
25 & Calyx length and width (mm) \\
26 & Standard length and width (open flower) (mm) \\
27 & Keel length and width (open flower) (mm) \\
28 & Wing length and width (open flower) (mm) \\
29 & Stamen (9) +1 length (mm) \\
30 & Carpel and Ovary length (mm) \\
31 & First visible fruit time (d) \\
32 & Pod maturation time (d) \\
33 & Pod length and width (cm) \\
34 & Number of pods /inflorescence \\
35 & Number of seeds/pod \\
36 & Seed yield/plant (g) \\
\hline
\end{tabular}




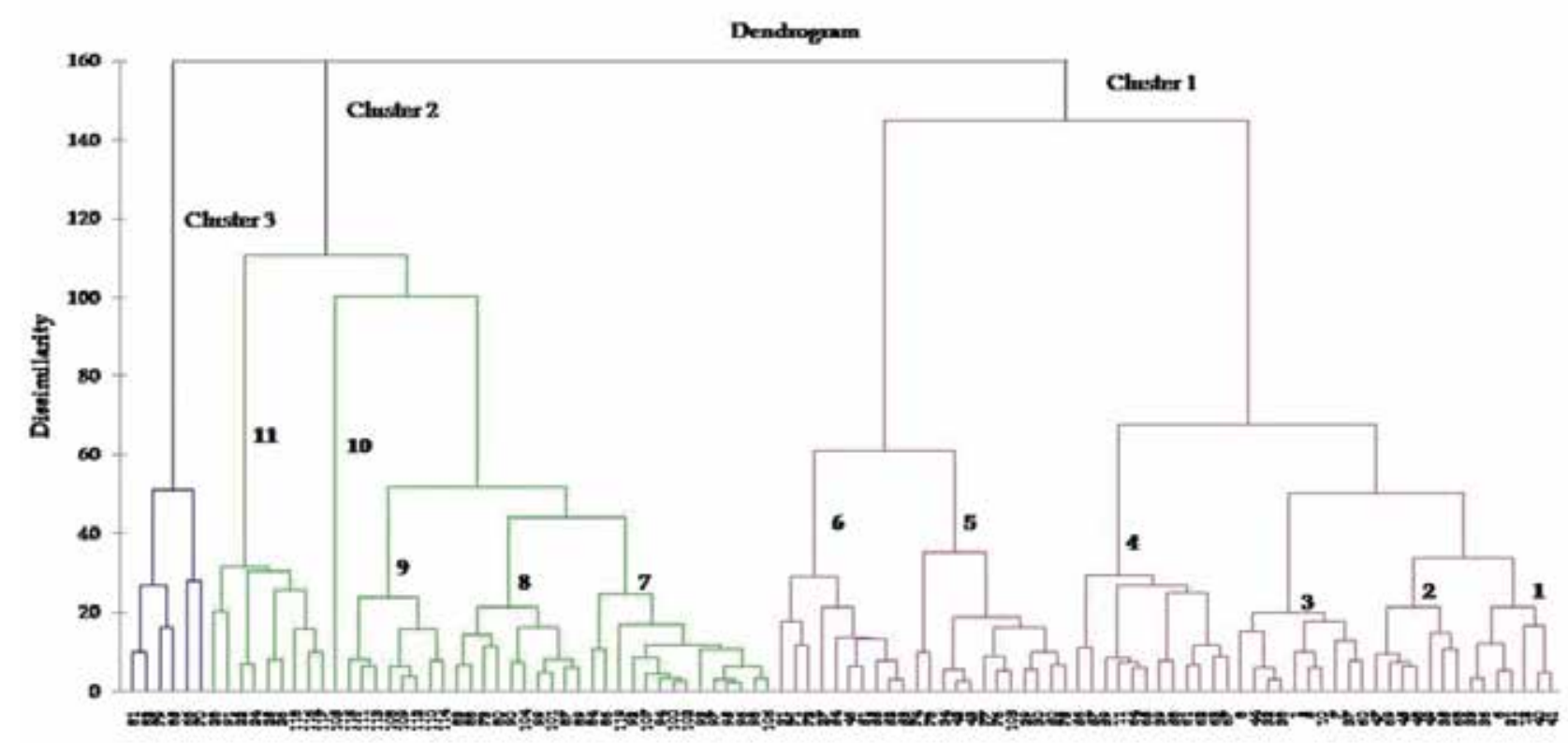

Fig. 1. Dendrogram built based on seed and seedling, vegetative and reproductive descriptors

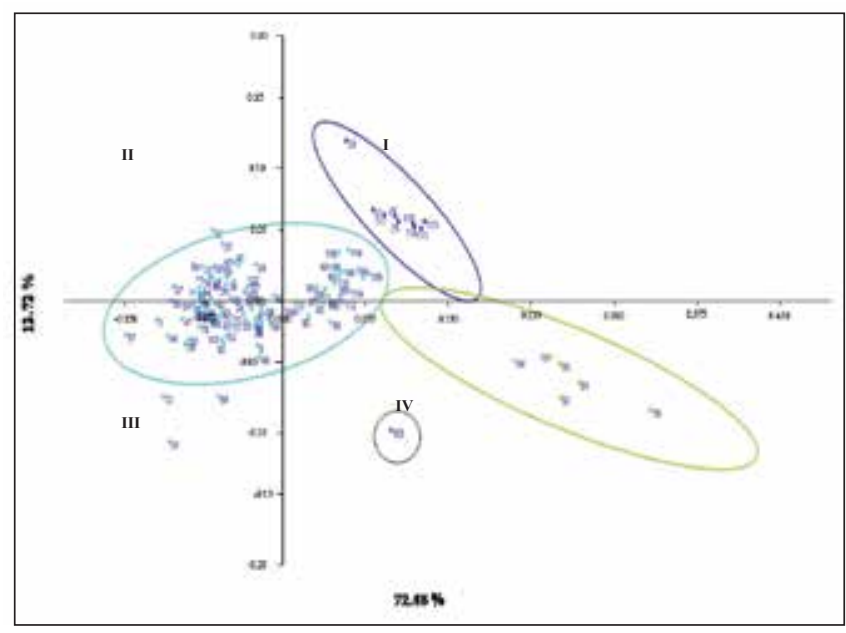

Fig. 2. Two dimensional graph representing accessions in the Principal Component Analysis based on seed and seedling, vegetative and reproductive descriptors

of Sesbania. The composition of other sub-clusters (\#1-9) showed a great variability in different analyses; this might indicate that these accessions may belong to same species with wide morphological variations (Chanda et al., 2019a). The result of present study is supported by the recent molecular phylogenetic study of Sesbania. Farruggia et al. (2018) had reported the close relation between $S$. cannabina and $S$. rostrata. Sesbania rostrata might be a probable ancestor of S. bispinosa and S. sesban; and three accessions of the polyploid S. bispinosa are scattered throughout the Pantropical clade (Fig. 3 in Farruggia et al. 2018). Along with reproductive/floral morphological descriptors, leaflet number and size, seed size and colour, and growth habit are emerged as important descriptors for grouping of Sesbania species (Evans, 1990; Heering, 1994; Heering et al., 1996; Veasey et al., 2001).

The two dimensional scattered plot distribution of PCA explained $85.20 \%$ of total variation. The first and second principal components explained $72.48 \%$ and $12.72 \%$ of the variations with high Eigen value 9.1 and 1.7, respectively (Fig. 2). The descriptors viz. seedling height, inter-node number/seedling, number of leaf/seedling, leaf length and width, leaflet length, seedling biomass yield, plant height, number of branch/plant and number of pods/plant, had more influence (score $>0.31$ ) on $\mathrm{PC} 1$; and descriptors viz. leaflet length and width, carpel and ovary length, pod length, number of seeds/pod and1000-seed weight, on PC2 (data not shown here). The majority of Sesbania accessions were concentrated near the centre point $(0,0)$ of the PCA graph in all four quadrates. Accession \#25, 26, 28, 91, 111, 113, 115, 116, and 117 were located very closely on the upper part of right quadrate I, while the accession \#66, 70, 79, 81, 82 and 85 were located very closely on the lower right side in quadrate IV and accession \#105 (the known S. rostrata) was also located in quadrate IV with a (distinct) isolated position (Fig. 2). These two clearly separated groups, comprises of six (\#66, 70, 79, 81, 82 and 85) and nine (\#25, 26, 28, 91, 111, 113, 115, 116 
Table II. Dissimilarities distance between species and principal descriptors responsible for discrimination of different Sesbania species

\begin{tabular}{|c|c|c|c|}
\hline $\begin{array}{l}\text { Sl. } \\
\text { No. }\end{array}$ & $\begin{array}{l}\text { Comparing } \\
\text { species }\end{array}$ & $\begin{array}{l}\text { Dissimilarities } \\
\text { (a verage) }\end{array}$ & Highest discriminating descriptors \\
\hline 1. & $\begin{array}{l}\text { S. bispinosa and } \\
\text { S. cannabina }\end{array}$ & $10.52 \%$ & $\begin{array}{l}\text { Leaf length, leaflets pair/leaf, standard length and } \\
\text { width, wing length, number of pods/plant }\end{array}$ \\
\hline 2. & $\begin{array}{l}\text { S. bispinosa and } \\
\text { S. sesban }\end{array}$ & $23.69 \%$ & $\begin{array}{l}\text { Leaf length, leaflets pair/leaf, standard length and } \\
\text { width, number of pods/plant }\end{array}$ \\
\hline 3. & $\begin{array}{l}\text { S. bispinosa and } \\
\text { S. rostrata }\end{array}$ & $14.68 \%$ & Leaf length , leaflets pair/leaf, number of pods / plant \\
\hline 4. & $\begin{array}{l}\text { S. cannabina } \\
\& \text { S. sesban }\end{array}$ & $18.79 \%$ & Standard width and length, number of pods / plant \\
\hline 5. & $\begin{array}{l}\text { S. cannabina } \\
\& \quad \text { S. rostrata }\end{array}$ & $14.37 \%$ & Leaf length, leaflets pair / leaf, number of pods / plant \\
\hline 6. & $\begin{array}{l}\text { S. sesban and } \\
\text { S. rostrata }\end{array}$ & $12.77 \%$ & Leaf length, number of leaves/plant, biomass yield \\
\hline
\end{tabular}

and 117) accessions, may belong to two separate Sesbania species. Accession \#105 the known foreign (check) species, $S$. rostrata, was located distinct separate position on the scatter plot distribution in quadrate IV. The rest ninety accessions, located very closely near the centre point $(0,0)$ of the PCA graph, may belong to another species of Sesbania (Fig. 2). Chanda et al. (2018a, b) reported that the accession $\# 70,79,81,82$ and 85 were always very closely located and these accessions remained in the same group. The principal component graph revealed that these are close together and being similar when related to another variable. The accessions were not more diverse from each other as they are overcrowded in the same plot area. It indicates that almost the accessions have similar quantitative characters with respect to vegetative, reproductive and mature traits of same species. The PCA technique acceptable the identification of a connection between variables, thus reducing the dimensionality of the data sets (Hammer-Muntz et al., 2001). It is an authoritative method for model appreciation that attempts to explain the variance of a large set of inter-correlated variables and transforms them into a smaller set of independent variables. Shim et al. (2016) stated that germplasms could be classified based on the variation of morphological traits using principal component and clustering analysis. Heering et al. (1996) reported that the first two components of the PCA, using mean values of the 15 identified variables of $S$. sesban explained $81 \%$ of the total variation. Added the principal component was mainly related to the number of leaflet pair/leaf and the length of the leaflets.
The comparison between the AHC analysis and PCA, the dendrogram has identified some similarities/dissimilarities (through clustering) among the collected Sesbania accessions (Fig. 1), however, the PCA detect these relationships more precisely (Fig. 2). Based on clustering analyses the collected 106 accessions were divided into 4 groups - group I (90 accessions), group II (9 accessions), group III (6 accessions) and group IV (the only accession) (Figs 1-2). After consulting with qualitative descriptors e.g., colour and spots on corolla components (standard, wing and keel), torulose pod, etc., these four groups had confirmed (/identified) as S. bispinosa (90 accessions), S. cannabina (9 accessions), S. sesban (6 accessions) and the known $S$. rostrata. Heering et al. (1996) separated 108 accessions of $S$. sesban on the basis of leaflet number and size, standard and pod length. Evans (1990) reported that the varieties of bicolor are very similar to sesban, however, differs only in flower colouration (Karachi, 1993). The AHC dendrogram has detected the close similarities between $S$. rostrata (sub-cluster \#10) and $S$. cannabina (sub-cluster \#11) (Farruggia et al., 2018); however, the PCA is capable to distinguish 4 different Sesbania species more precisely (Figs 1-2).

The dissimilarities were computed among the collected accessions and it calculates the distance between each pair of species of a unit in the current ordination. The mean morphological dissimilarities among the species was $15.8 \%$; descriptors mainly responsible for the discrimination were number of leaves/plant, leaflets pair/leaf, leaf length, standard 
length and width, wing length, number of pods/plant and biomass yield (Table II). The lowest average discrimination value of $10.52 \%$ was observed between the species $S$. bispinosa and S. cannabina and the dissimilarities descriptors were leaflets pair/leaf, leaf length, standard width and length. The lowest discriminating distance might be due to overlapping or similarities in morphological descriptors. The highest average discrimination value of $23.69 \%$ was observed between S. bispinosa and S. sesban and the dissimilarities descriptors were number of pods/plant, leaflets pair/leaf and leaf length (Table II). It could be attributed to the differences in morphological descriptors between themselves. The discriminating value of $14.68 \%$ occurred between $S$. bispinosa and $S$. rostrata and main dissimilarities descriptors were number of pods/plant, leaflets pair/leaf and leaf length. Between S. cannabina and S. sesban, the discriminating value was $18.79 \%$ and main dissimilarities descriptors were standard width and length and number of pods/plant (Table II). The discriminating distance between $S$. cannabina and S. rostrata was $14.37 \%$ and main dissimilarities descriptors were number of pods/plant, leaflets pair/leaf and leaf length. The dissimilarities value of $12.77 \%$ was found between $S$. sesban and $S$. rostrata, and the dissimilarities descriptors were biomass yield, number of leaves/plant and leaf length (Table II). Identical findings were reported by Srivastava and Kumar (2014) who mentioned that the morphology of S. bispinosa and S. cannabina are very confusing in terms of agronomic view. The differences between $S$. bispinosa and S. cannabina in particular are small and can mainly be found in the morphology of the keel (Srivastava and Kumar, 2014).

\section{Conclusion}

Based on multivariate analyses, the collected Sesbania accessions were divided into four distinct groups; and after consulting with qualitative descriptors, these (groups) are identified as S. bispinosa (90 accessions), S. cannabina (9 accessions), $S$. sesban (6 accessions) and the known $S$. rostrata. Multivariate analyses are thus emerged as an effective tool for identification of Sesbania accessions. Among these four species, the highest discriminating distance was observed between $S$. bispinosa and S. sesban, and the lowest was in $S$. bispinosa and $S$. cannabina.

\section{Acknowledgement}

We acknowledge the financial support of the Ministry of Science and Technology, Government of the People's Republic of Bangladesh.

\section{References}

Ahmed ZU, Hassan MA, Begum ZNT, Khondker M, Kabir SMH, Ahmad $M$ and Ahmed ATA (2009), Encyclopedia of Flora and Fauna of Bangladesh, Vol. 8. Angiosperms: Dicotyledons (Fabaceae-Lythraceae), Asiatic Soc. Bangladesh, Dhaka, pp 1-474.

Chanda SC (2019), Agro-morphological characterization of dhaincha genetic resources of Bangladesh for the improvements of soil nutrients status, $P h D$ Thesis, Bangladesh Agricultural University, Mymensingh, Bangladesh, pp 1-172

Chanda SC, Hossain MA, Rahman MM, Shamsuzzaman ANM and Sarwar AKM Golam (2019a), Regional variation in agro-morphological descriptors of Sesbania bispinosa (Jacq.) W. Wight, Bangladesh J Bot. 48: 289-295. DOI: 10.3329/bjb.v48i2.47551

Chanda SC, Islam N, Tinne FJ and Sarwar AKM Golam (2018a), Screening of Sesbania accessions based on seed germination and seedling biomass, Arch Agric Environ Sci. 3: 137-142. DOI: 10.26832/ 24566632.2018.030206

Chanda SC, Mridul A-M, Sagar A and Sarwar AKM Golam (2017), Germination and seedling growth of Sesbania species as influenced by seed size, Progress Agric. 28: 316-322. DOI: 10.3329/pa.v28i4.36371

Chanda SC, Prodhan AKMA and Sarwar AKM Golam (2018b), Morphological descriptors of seed and seedling for identification of dhaincha (Sesbania spp.) accessions, Bangladesh J Bot. 47: 237-246

Chanda SC, Sagar A, Islam MM, Hossain MA and Sarwar AKM Golam (2019b), Phenology and reproductive biology of three Sesbania species, Int J Min Fruits Med Plants 5: 29-37.

Evans DO (1990), What is Sesbania? Botany, taxonomy, plant geography and natural history of the perennial members of the genus In: Perennial Sesbania Species in Agroforestry Systems, Eds. Macklin B and Evans DO, Nitro Fix Tree Assoc, Waimanalo, Hawaii, USA, pp 5-19.

Farruggia FT, Lavin M and Wojciechowski MF (2018), Phylogenetic systematics and biogeography of the Pantropical genus Sesbania (Leguminosae), Econ Bot. 43: 414-429. DOI: 10.1600/036364418X697175 
Hammer-Muntz O, Harper D and Ryan PV (2001), Past: Paleontological Statistics Software Package for Education and Data Analysis, Palaeontologia Electronica 4: 1-9. http://palaeo-electronica. org/ 2001 1/past/issue1_01.htm.

Heering JH (1994), The reproductive biology of three perennial Sesbania species (Leguminosae), Euphytica 74: 143-148. DOI: 10.1007/BF00033780

Heering JH, Nokoe S and Jemal M (1996), The classification of a Sesbania sesban (ssp. sesban) collection. I. Morphological attributes and their taxonomic significance, Trop Grass. 30: 206-214.

Kane A, Achir N, Cisse M, Pallet D, Sakho M and Dornier M (2019), Identification of roselle varieties through simple discriminating physicochemical characteristics using multivariate analysis, Food Sci Technol. (Campinas) 39: 321-327. DOI: 10. 1590/1678457x.29417

Karachi M (1993), Screening of Sesbania sesban accessions for growth, biomass yield, seed production and plant survival in Tobora, Tanzania, Proc African Feed Resour Net (AFRNET) Works., Nairobi, Kenya, 9-14 September, 1991, pp 66-74.

Karp A, Kresovich S, Bhat K, Ayad W and Hodgkin T (1997), Molecular tools in plant genetic resources conservation: a guide to the technologie, IPGRI Technical Bulletin No. 2. International Plant Genetic Resources Institute, Rome, Italy.

Lever J, Krzywinski M and Altman N (2017), Principal component analysis, Nat Methods 14: 641-642. DOI: 10. 1016/0169-7439(87)80084-9

Mehraj H and Shimasaki K (2017), Hierarchical cluster, euclidean distance and principal component analysis based on phenotypic characters of Hosta, J Biosci Agric Res. 12: 1029-1035. DOI: 10.18801/ jbar. 120217.125

Nurul AMR, Mohamad RB, Puteh AB, Abdullah NAP and Morshed MM (2014), Morphological characterization and identification of two Sesame (Sesamum spp,) ecotypes in Malaysia, Vegetos 27: 161-169. DOI: 10.5958/2229-4473.2014.00084.6

Sarwar AKM Golam (2018), Sesbania-An underutilized, miracle plant (Invited Lecture). Proc ICCBSA 13-16 Dec., Jorhat (Assam), India. p 124.

Shim KB, Shin SH, Shon JY, Kang SG, Yang WH and Heu SG (2016), Classification of a collection of Sesame germplasm using multivariate analysis, J Crop Sci Biotech. 19: 151-155. DOI: 10.1007/ s12892015-0099-4

Sneath PHA (1969), Evaluation of clustering methods In: Numerical Taxonomy, Ed. Cole AJ, Academic Press, New York, pp 257-271.

Srivastava N and Kumar G (2014), Morphotaxonomy and phenology of three different accessions of Sesbania cannabina Poir., Intl Res J Biol Sci. 3: 70-72.

Veasey EA, Schammass EA, Vencovsky R, Martins PS and Bandel G (1999), Morphological and agronomic characterization and estimates of genetic parameters of Sesbania Scop. (Leguminosae) accessions, J Genet Mole Biol. 22: 81-93. DOI: 10.1590/ S141547571999000100017

Veasey EA, Schammass EA, Vencovsky R, Martins PS and Bandel G (2001), Germplasm characterization of Sesbania accessions based on multivariate analysis, Genet Res Crop Evol. 48: 79-90. DOI: 10.1023/ A:1011238320630 